\title{
Some New Correlations of Q-Value with Rock Mechanics Parameters in Underground Oil Storage Caverns
}

\author{
Fang Lin ${ }^{\mathrm{a}, \mathrm{c}}$, Hebing Luan ${ }^{\mathrm{b} *}$, Yanhua Zeng ${ }^{\mathrm{c}}$, Zhibin Zhong ${ }^{\mathrm{d}}$ \\ ${ }^{a}$ National Engineering Laboratory for Green \& Safe Construction Technology in Urban Rail Transit, Beijing Urban Construction, \\ Design \& Development Group Co. Ltd., Beijing, China. \\ ${ }^{b}$ State Key Laboratory of Hydroscience and Engineering, Department of Hydraulic Engineering, Tsinghua University, Beijing, China. \\ ${ }^{c}$ MOE Key Laboratory of Transportation Tunnel Engineering, Southwest Jiaotong University, Chengdu, Sichuan, China. \\ ${ }^{d}$ China Railway Eryuan Engineering Group Co. Ltd, Chengdu, Sichuan, China.
}

Received 26 July 2017; Accepted 30 August 2017

\begin{abstract}
Q-system is a preferred alternative method of rock mass classification for underground oil storage caverns where stable lithological rocks are widely distributed. In this paper, correspondences between important input rock mechanics parameters (friction angle, cohesion, tensile strength, Poisson's ratio, deformation modulus) and Q values were investigated, thereby bringing convenient to rapidly obtain available parameters when it's hard to collect measured field data in underground storage projects basically with similar lithology. The proposed correlations were verified through numerical simulation and on-site monitoring measurement. In addition, comparison of different criteria among Q-system and other codes for rock mass classification has been made to help for making a preliminary evaluation of rock mass quality in the practical engineering. Finally, the behaviours of surrounding rock deformations under different $\mathrm{Q}$ values were analysed by using FLAC3D code with the calculating parameters suggested in this paper, and the calculation results match well with measured values in situ. Above results will not only guide the construction but also could be relevant to other underground storage engineering under similar geological conditions.
\end{abstract}

Keywords: Underground Oil Storage Caverns; Rock Mechanics Parameters; Q-System.

\section{Introduction}

At present, water sealed underground petroleum storage caverns in rock is the main way used for strategic petroleum reserve. Constructing large water sealed underground oil storage caverns in coastal regions where granite, welded stuff and other stable lithological rocks are widely distributed, is no doubt a project with better comprehensive economic effect. It has been reported to have many advantages in construction cost, environmental protection, and operation safety [1-4]. The earliest reference to the use of a rock mass classification system for engineering purposes is the rock load theory that was published by Terzaghi [5]. Since then, many systems have been developed, e.g. the Rock Quality Designation (RQD) system [6], the Rock Mass Rating (RMR) system [7-9], the Norwegian Geotechnical Institute Qsystem (Q) [10], the Rock Structure Rating (RSR) system [11], the Geological Strength Index (GSI) [12], and the New Austrian Tunneling Method (NATM) [13], to improve methods for designing structural support systems. Q-system is a preferred alternative method of rock mass classification for oil storage projects.

The Q-system developed originally at the Norwegian Geotechnical Institute by Barton, Lien, Lunde [13], and evolved to its final state by Grimstad and Barton [14] with minor updates by Barton [15]. Some researchers have focused on

\footnotetext{
* Corresponding author: luanhebing@hotmail.com

$>$ This is an open access article under the CC-BY license (https://creativecommons.org/licenses/by/4.0/).

(C) Authors retain all copyrights.
} 
correlations between different rock mass classification systems and Q-system, especially RMR system [16-20], some have concentrated on improving [15] and correcting misuse [21] of Q-system, while there have been few studies with regard to the relationships of Q values with general rock mechanics parameters. Rock formations cannot often be treated as isotropic and homogeneous. There are a number of important parameters to consider in the fracturing of rock. Some of these are fracture toughness, in situ stress, Poisson's ratio, and Young's modulus [22]. So the rock mechanics parameters e.g. friction angle, cohesion and tensile strength, are often not well known or easily measured parameters. Field tests to determine these parameters directly are time consuming, expensive and the reliability of the results of these tests is sometimes questionable. However, they are required input parameters for different types of numerical analyses, therefore it is very important to obtain realistic values of these parameters for any analysis which involves deformations. Empirical relationships and functions of rock mass deformation modulus on the basis of classification schemes have been summarized and proposed by Read et al, Mitri, Hoek [23-25]. While there is few study on relationships among Q values and friction angles, cohesion, tensile strength, Poisson's ratio, deformation modulus, which are very useful for initial estimation when field parameters are hard to acquire in underground storage projects. Therefore, this paper aims to investigate the correspondences between $\mathrm{Q}$ values and general rock mechanics parameters (friction angles, cohesion, tensile strength, Poisson's ratio, deformation modulus), thus to find some correlations which can be used in underground storage projects basically with similar lithology.

\section{Site Description}

The rock in the study area consists primarily of Proterozoic and Cretaceous granite. Based on cores obtained from drill holes in the area, the predominant rock types are granite. Other minor rock types include diorite and amphibolite, which comprise less than $10 \%$ of the overall rock mass. The rock mass was classified based on the Q-system. More than $80 \%$ of the Q-values correspond to rock of fair to very good rock mass quality. Generally, competent and unweathered rock provides excellent rock mass conditions for cavern construction.

Groundwater is present in the form of pore water and fracture water. The average annual precipitation in the area over the past 20 years has been $532.7 \mathrm{~mm}$, and heavy rains tend to occur between June and September, when more than $76 \%$ of the annual precipitation occurs. Wind direction is N-NW in winter and S-SW in summer, predominant direction is SSW, average wind velocity is $3.8 \mathrm{~m} / \mathrm{s}$ throughout the year.

Based on field test data, the dominant joint system of the whole field area strikes NNW and NEE, $270^{\circ} \angle 30^{\circ}, 150^{\circ}$ $\angle 75^{\circ}, 85^{\circ} \angle 60^{\circ}, 330^{\circ} \angle 30^{\circ}$ and approximately horizontal joints are mainly developed. According to geological advanced exploration drilling test, we found most of rocks were micro-weathered granites with developed closed joint fissures. Tunnel face was wet with a high self-stabilization, without chipping in close jointed area.

The underground facility at this site will consist of storage caverns, access tunnels and water curtain tunnels. Figure 1. shows the layout of the underground structures. Eight storage caverns, which are to be left unlined aside from a layer of shotcrete, are aligned parallel to one another. Each of the searched caverns is $19 \mathrm{~m}$ wide at the base, $24 \mathrm{~m}$ tall and 734 $\mathrm{m}$ long. The access tunnels, which are also arched, are $8 \mathrm{~m}$ wide and $8 \mathrm{~m}$ tall. Their elevations vary from El. $0 \mathrm{~m}$ at the entrance to El. $-80 \mathrm{~m}$ at the floor level of the storage caverns. The water curtain tunnels, which are also arched, are $6.5 \mathrm{~m}$ wide and $6 \mathrm{~m}$ tall. The water curtain tunnels are at an elevation of El. $-32 \mathrm{~m}$, which is $24 \mathrm{~m}$ above the storage caverns. The tunnels and caverns are being excavated using the drill-and-blast method.

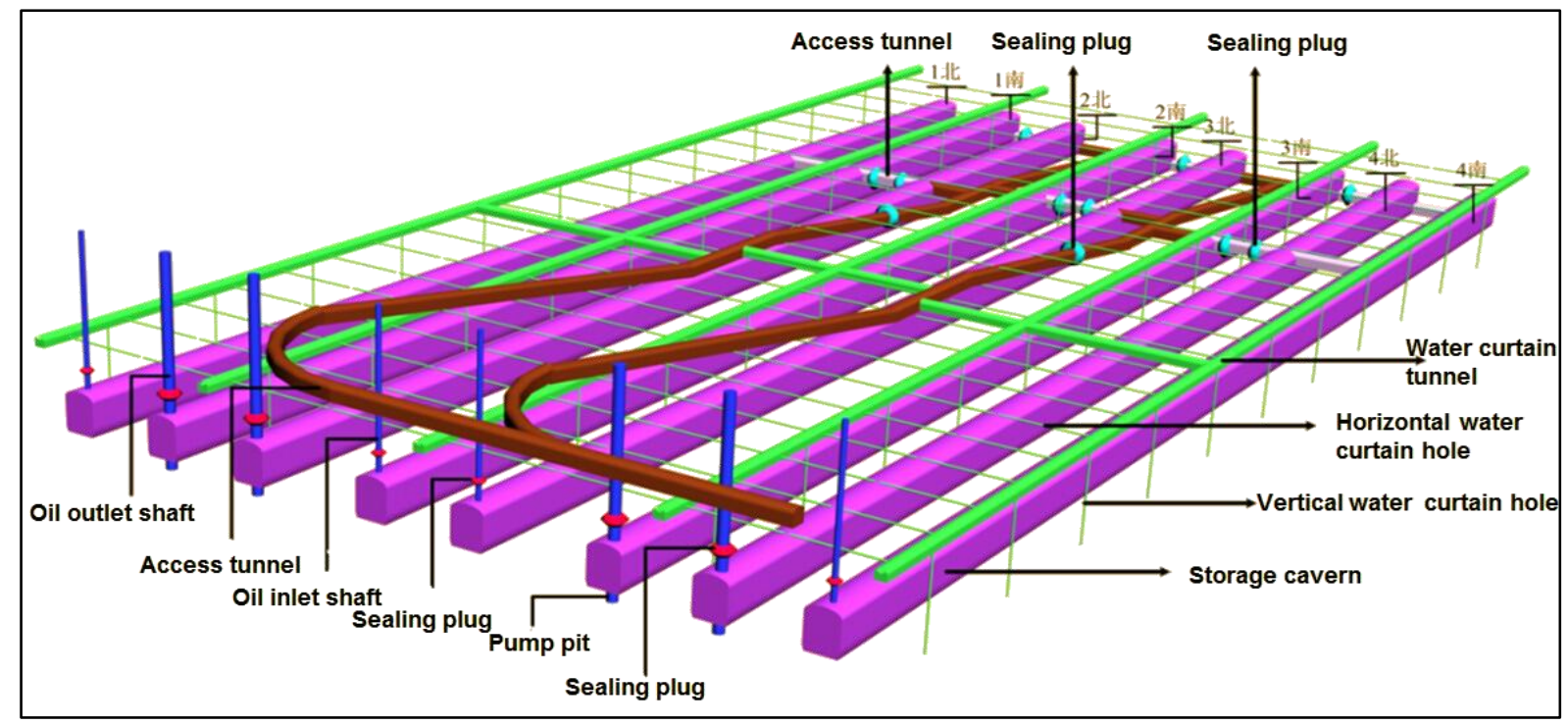

Figure 1. Layout of underground structures of the storage facility 


\section{Correlations of $q$ Values with Rock Mechanics Parameters}

This study collected six relevant Q-parameters (RQD, SRF, $J_{\mathrm{n}}, \mathrm{J}_{\mathrm{r}}, \mathrm{J}_{\mathrm{a}}, \mathrm{J}_{\mathrm{w}}$ ) based on spot geological sketch of current underground oil storage project, and general rock mechanics parameters i.e. friction angle, cohesion, uniaxial tensile strength, tensile strength, shear modulus, deformation modulus and poisson's ratio were also derived by field test and laboratory experiment. Different mathematic models were adopted to investigate the correlations between these rock mechanics parameters and $\mathrm{Q}$ values by using statistical fitting methods. In view of the importance of the site investigation phase that precedes preliminary design, and which gives indications of the need for additional hydrogeological information, we will start this exploration of Q-correlations with an investigation of rock mechanics parameters in underground oil storage caverns.

\subsection{Friction Angles and Cohesion}

Unlike soils (both cohesive and cohesionless) the magnitude of the angle of internal friction (sometimes refer to as the angle of shear strength) and cohesion vary and depend on the current state of stress in the rock body. All rock masses contain discontinuities such as bedding planes, joints, shear zones and faults. At shallow depth, where stresses are low, failure of the intact rock material is minimal and the behavior of the rock mass is controlled by sliding on the discontinuities. So it is necessary to understand the factors that control the shear strength of the discontinuities which separate the blocks. Exploring a deeper meaning behind the six components of Q, Barton [15] found the ratio $\mathrm{J}_{\mathrm{r}} / \mathrm{J}_{\mathrm{a}}$ closely resembled the dilatant or contractile coefficient of friction for joints and filled discontinuities, the 'frictional component' of a rock mass was defined finally with the necessary addition of $\mathbf{J}_{\mathrm{w}}$. The 'cohesive component' was expressed with the remaining Q-parameters and $\sigma_{c}$. Nevertheless, comparing the tested results with the Barton's theoretical ones, the conclusion shows great scatterness (see Figure 2. and Figure 3).

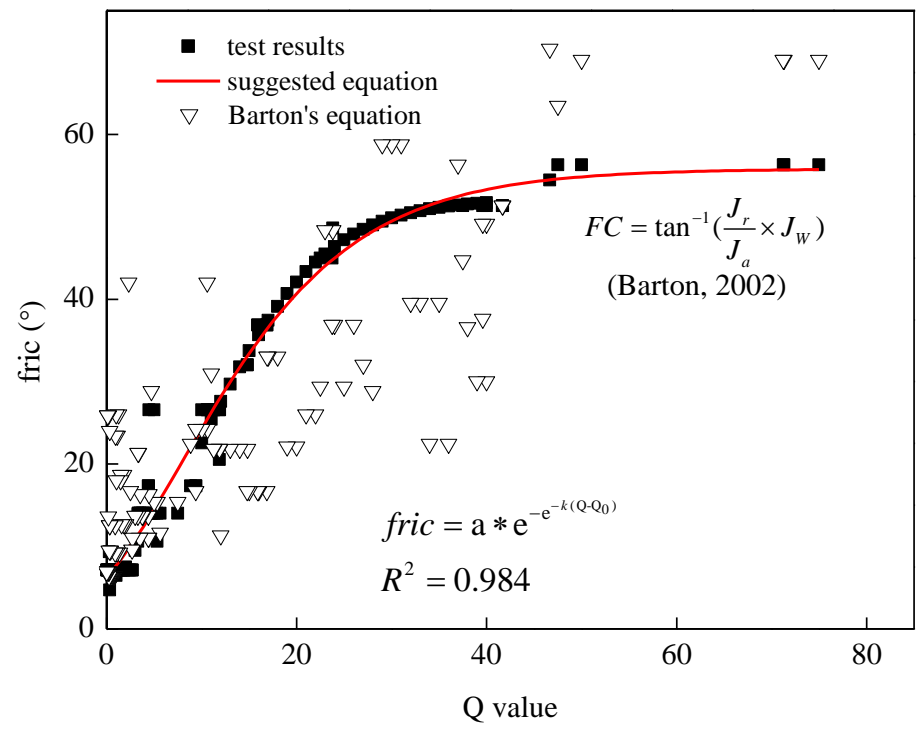

Figure 2. Correlation between $Q$ and fric

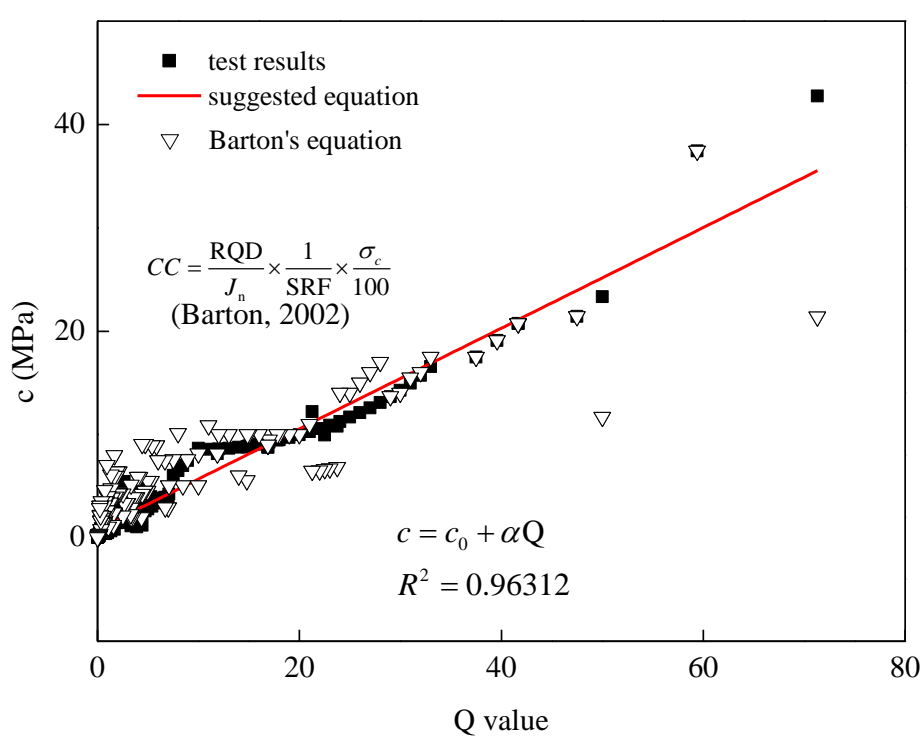

Figure 3. Correlation between $Q$ and cohesion 
Addressing our attention to the whole six Q-parameters, we may observe that the quotient $\left(R Q D / J_{n}\right)$ represents the relative block size, the product of the interaction between the joint orientation, spacing and persistence of that rock mass. $J_{r} / J_{a}$ represents the roughness and frictional characteristics of the joint walls with or without filling materials, is a useful characterization of the condition of discontinuities. $J_{w} / S R F$ is a complicated, empirical ratio consisting of two groups of stress parameters, represents the relative effect of water, faulting, stress ratio, squeezing or swelling. We may see, all these Q-parameters take care of shear strength of the discontinuities, thus affect the cohesion and the angle of internal friction for rock. So we tried to discover whether there was a connection between fric, $c$ and $\mathrm{Q}$ values.

As can be seen from Figure 2, SGompertz model was chosen to describe the relationship between Q and friction angle. The results show that the relevance is very high with R-square as 0.984 except a few items. The correlation was suggested:

$$
\text { fric }=a * e^{-e^{-k\left(Q-Q_{0}\right)}}
$$

Where $k=0.096, Q_{0}=8.08, a=55.8$, and perfect correlations were displayed between $10 \leq \mathrm{Q} \leq 40$ particularly.

The calculated Q values was found to have a linear effect on the measured values of cohesion (see Figure 3). There is significant relationship between $\mathrm{Q}$ and c with a high correlative coefficient as $R_{2}=0.96312$, thereby Equation 2 . was proposed to calculate $\mathrm{Q}$ values or $c$ when making a quick estimation in construction site.

$c=c_{0}+\alpha Q$

Where $c_{0}=0.83, \alpha=0.4866$.

\subsection{Tensile strength}

Rock material generally has a low tensile strength. The low tensile strength is due to the existence of microcracks in the rock, which may also be the cause of rock failing suddenly in tension with a small strain. We were pleased to discover that $Q$ values of current oil storage caverns are obviously relevant to test tensile strength (see Figure 4). The correlation described by means of the linear fit, with a very high $R$ square as 0.99996 , was suggested as follows:

$$
\text { ten }=\text { ten }_{0}+\beta Q
$$

Where $\operatorname{ten}_{0}=3.47, \beta=0.14$.

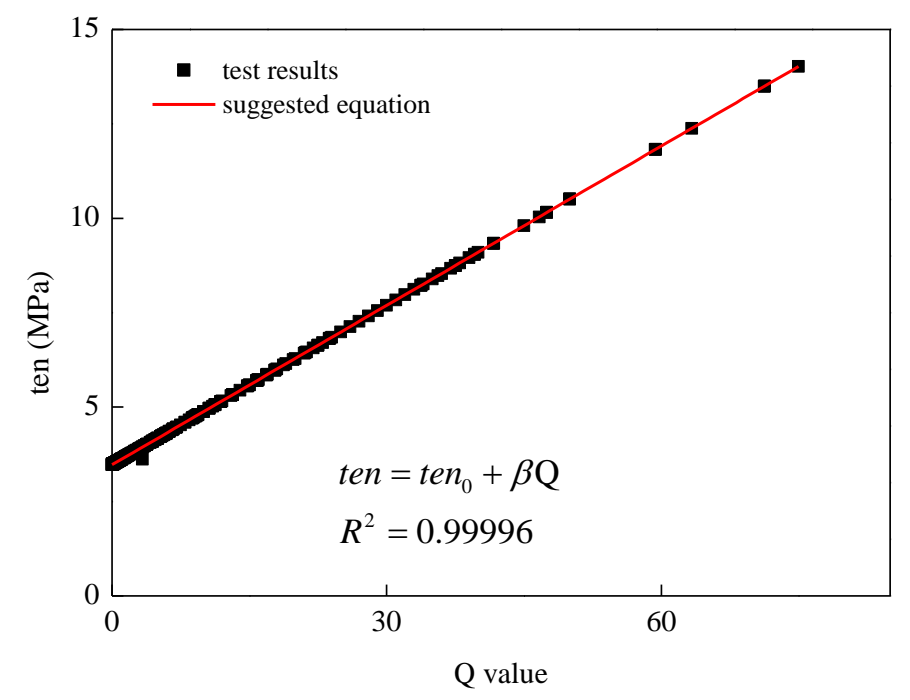

Figure 4. Correlation between $Q$ and ten

\subsection{Deformation Modulus}

Similar to strength, deformation modulus of rock materials varies widely with rock type, for extremely hard and strong rocks, deformation modulus can be as high as $100 \mathrm{GPa}$. Based on fitted empirical equations for estimation of rock mass modulus summarized by Hoek [25], we tried to correlate deformation modulus with $R M R$ values ( $Q$ and $R M R$ systems are based on very similar properties [20]), when we found it's hard to make a direct way to connect deformation modulus with Q values. The results (see Figure 5) show the excellent agreement between $R M R$ and deformation modulus by using linear fit in two segments: RMR $\geq 44$ and RMR<44. Compared with Hoek's correlation (see Equation 4), equation (5) and (6) are more applicable to stable lithological rocks, most underground oil storage projects located, with fairly high $R^{2}=0.99965$ and $R^{2}=0.9604$ respectively $[25,26]$. 


$$
\begin{aligned}
& E=(1-D / 2) \sqrt{\sigma_{c i} / 100} \times 10^{((R M R-10) / 40)}, \mathrm{D}=0, \sigma_{c i}=100 \mathrm{MPa} . \\
& E=E_{1}+\alpha Q(\mathrm{RMR} \geq 44) \\
& E=E_{2}+\beta Q(\mathrm{RMR}<44)
\end{aligned}
$$

Where $E_{1}=-0.1752, E_{2}=-52.79, \alpha=0.05, \beta=1.20$.

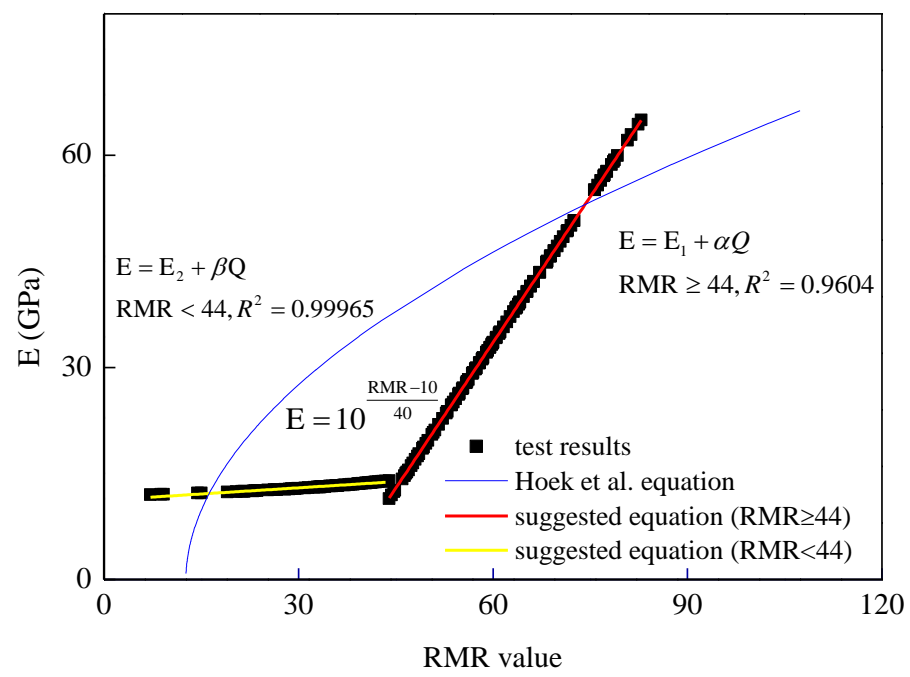

Figure 5. Correlation between $R M R$ and $E$

Collecting field measured data of $R M R$ values, regression analyses was made to study the relationship between $R M R$ and $\mathrm{Q}$ values in Log3P1model, with a highest correlative coefficient 0.99647 in current oil storage cavern among previous fitting equations (see Figure 6) [27-31], which is in close proximity to Bieniawski's equation. Following is the correlation:

$R M R=43.765+9.087 * \operatorname{In}(Q+0.0088)$

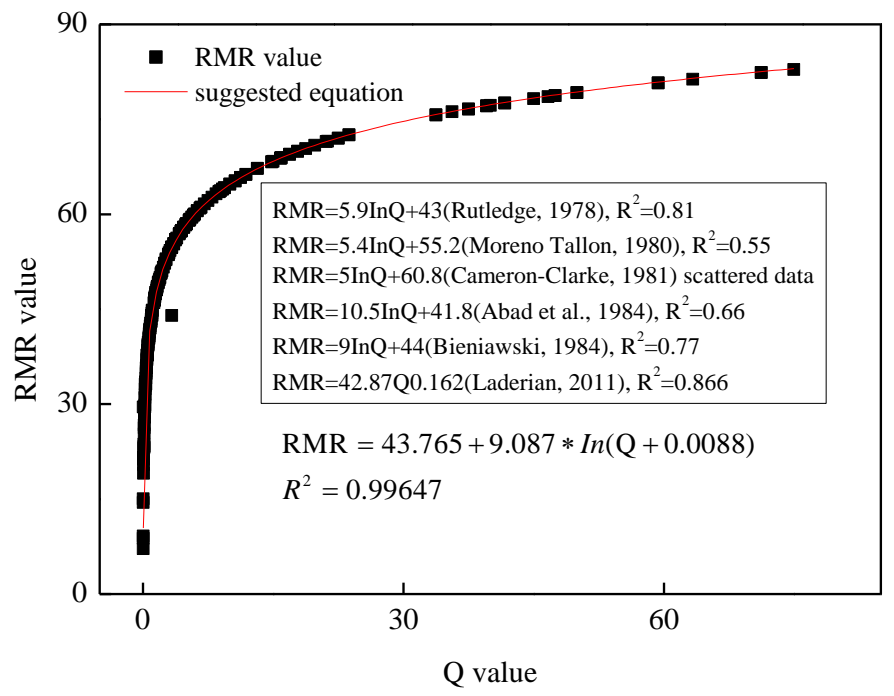

Figure 6. Correlation between $Q$ and $R M R$

\subsection{Poisson's Ratio}

Poisson's ratio reported for rocks vary in a narrow range, the value is between 0.15 and 0.4 for most rocks [32]. However, existence of fractures makes the behaviour of rock masses substantially different from that of intact rocks. The Poisson's ratio in fractured rock masses can be larger than typical values used in practice [33]. Hill 1 model was used to investigate if $\mathrm{Q}$ values were associated with poisson's ratio. Figure 7. describes the relationship between $Q$ values and ${ }^{v}$ with a high $R$ square as 0.95415 . The correlation was suggested:

$$
v=v_{0}-\alpha \frac{Q^{n}}{k^{n}+Q^{n}}
$$

Where $v_{0}=0.4645, \alpha=0.2647, k=17.67, n=1.9$. 


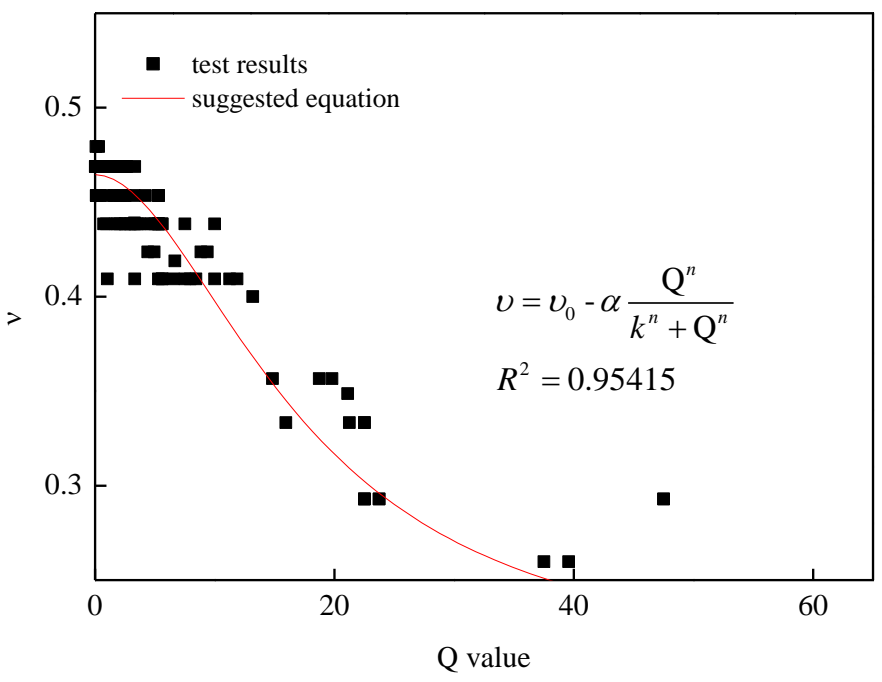

Figure 7. Correlation between $Q$ and $v$

\subsection{Comparison of Different Criteria Among Q-System and Other Codes For Rock Mass Classification}

Besides $R M R$ values, $B Q$ values were also collected to better understand the rock mass quality and applicability of Q-system in underground oil storage project. Table 1. shows comparison of classification factors for Q-system and other methods, where ' $\sqrt{ }$ ' means this factor is counted and ' $X$ ' means this factor is not counted. It can be seen from this table, BQ system takes all the 6 factors into account, and Q system loses sight of combinational relationships between tunnel axis and rock joins. And we made a 5-classes corresponding relation among these methods in Table 2. Collected field measured data of $Q$ and $R M R$ values and calculated $[B Q]$ values by field geological sketch, the rock was classified by $Q, R M R$, and $B Q$ systems in stratified sampling of this underground oil storage project, Appendix $C$ presents integrated classification results. We set 5 classes (I-V) (see Table 2) as an evaluation index to compare Q, RMR, and BQ systems. It can be seen that rock classification by Q-system has a high similarity with RMR-system, and the classification indicators and principles of $\mathrm{Q}, \mathrm{RMR}$ and $\mathrm{BQ}$ methods are approximate. When $\mathrm{Q}$ or RMR values are small, the same rock classification can be got as BQ method, while one grade deviation exists between $\mathrm{Q}$ or RMR method and BQ method when $Q$ or $R M R$ values are bigger. Above comparison helps to make a preliminary evaluation of rock mass quality in the practical engineering.

Table 1. Comparison of classification factors for different methods

\begin{tabular}{|c|c|c|c|c|c|c|c|}
\hline \multirow[b]{2}{*}{ Method } & \multicolumn{6}{|c|}{ Rock Classification Factors } & \multirow[b]{2}{*}{$\begin{array}{l}\text { Calculation } \\
\text { Methods Of } \\
\text { Factors }\end{array}$} \\
\hline & Strength & Integrity & $\begin{array}{l}\text { Structure } \\
\text { Character Of } \\
\text { Rock Mass }\end{array}$ & $\begin{array}{c}\text { Combinational } \\
\text { Relationships Between } \\
\text { Tunnel Axis And Rock } \\
\text { Joints } \\
\end{array}$ & $\begin{array}{l}\text { Underground } \\
\text { Water }\end{array}$ & $\begin{array}{c}\text { Initial } \\
\text { Ground } \\
\text { Stress }\end{array}$ & \\
\hline RMR & $\sqrt{ }$ & $\sqrt{ }$ & $\sqrt{ }$ & $\sqrt{ }$ & $\sqrt{ }$ & $x$ & plus-minus method \\
\hline Q & $\sqrt{ }$ & $\sqrt{ }$ & $\sqrt{ }$ & $x$ & $\sqrt{ }$ & $\sqrt{ }$ & product method \\
\hline BQ & $\sqrt{ }$ & $\sqrt{ }$ & $\sqrt{ }$ & $\sqrt{ }$ & $\sqrt{ }$ & $\sqrt{ }$ & $\begin{array}{c}\text { plus-minus \& } \\
\text { product method }\end{array}$ \\
\hline
\end{tabular}

Table 2. Comparison among classification index values for different methods

\begin{tabular}{cccccc}
\hline \multirow{2}{*}{ Values } & \multicolumn{5}{c}{ Surrounding Rock Classification } \\
\cline { 2 - 6 } & I & II & III & IV & V \\
\cline { 2 - 6 } & Very Good & Good & Fair & Poor & Extremely Poor \\
\hline RMR & $100 \sim 81$ & $80 \sim 61$ & $60 \sim 41$ & $40 \sim 21$ & $\leq 20$ \\
Q & $>40$ & $10 \sim 40$ & $1 \sim 10$ & $0.1 \sim 1$ & $<0.1$ \\
{$[\mathrm{BQ}]$} & $>550$ & $550 \sim 451$ & $450 \sim 351$ & $350 \sim 251$ & $\leq 250$ \\
\hline
\end{tabular}

\section{Q-System Application in Underground Oil Storage Tunnels Excavation}

Storage caverns with the height of 19 meters and the spacing of 24 meters have been excavated in three-step benching tunneling method. This paper has studied the surrounding rock deformations under different geological conditions (various $Q$ values) by using the fast Lagrangian analysis of continua software FLAC3D, with simulation parameters picked up in Equations 1-8, one computational sample is shown in Figure 8. Pre-processing module of ANSYS is used 
to build underground cavern group numerical model, meshing and group definition is also finished in this module, and then this meshed model was imported into FLAC3D for calculation. Vertical and horizontal displacements are constricted in bottom and surrounding boundaries respectively. The upper boundary, the actual ground, is free. No other loads are applied to the model except for gravity and horizontal stress and every cyclical footage is $4 \mathrm{~m}$. Afterwards, the numerical simulation results were compared with monitoring data, which could verify the accuracy of these equations.
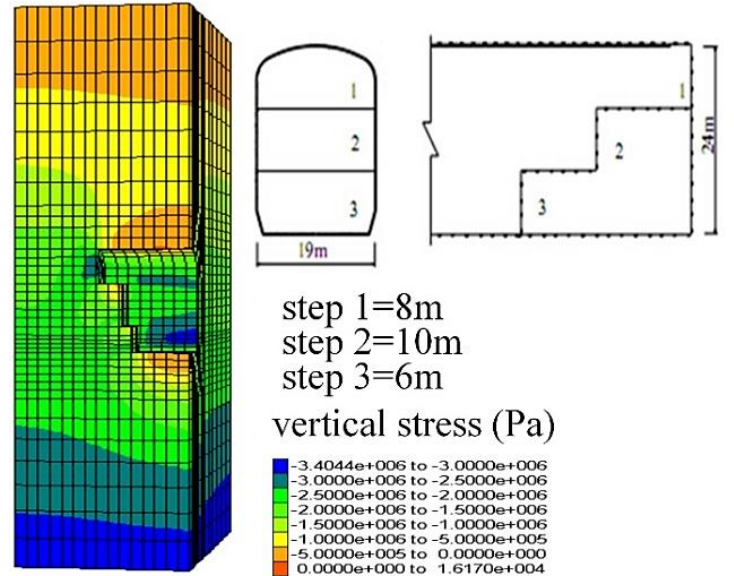

step $1=8 \mathrm{~m}$

step $2=10 \mathrm{~m}$

step $3=6 \mathrm{~m}$

vertical stress $(\mathrm{Pa})$
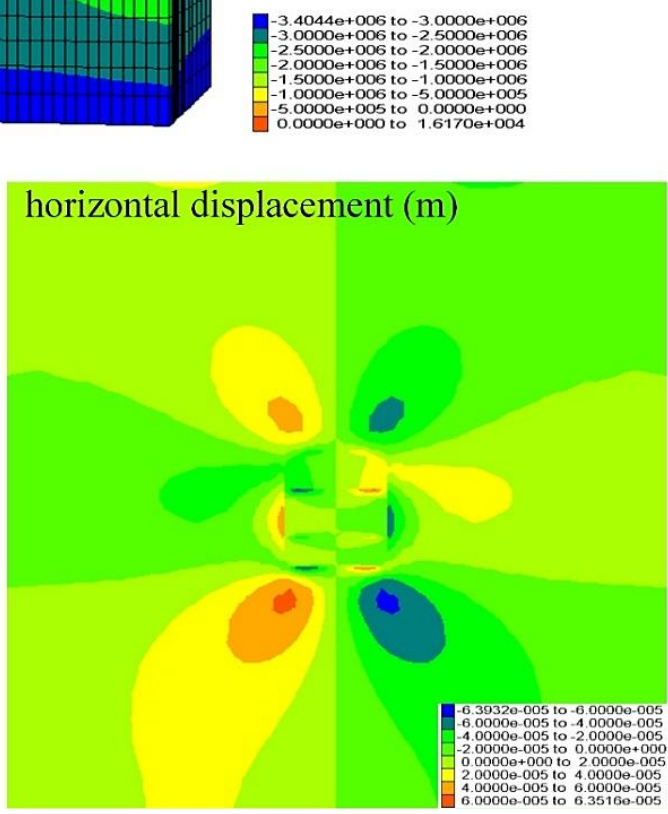
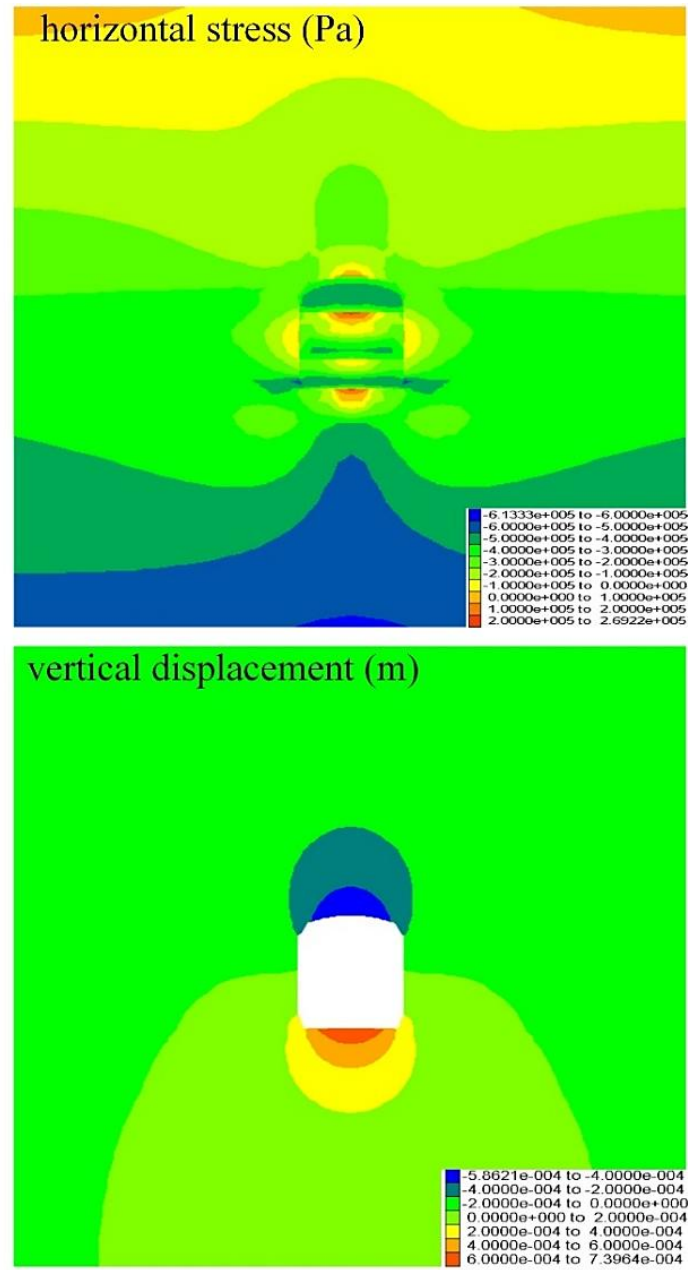

Figure 8. One computational model case of $Q=39.6$

Figure 9. displays plans of current underground oil storage caverns with the locations of faults and dominant joint orientations and also presents 10 typical sections for simulation and monitoring measurement. We selected 22 monitoring sections altogether in tunnels $1 \mathrm{~N}, 1 \mathrm{~S}, 2 \mathrm{~N}$ and $2 \mathrm{~S}$, which should cover most use cases. And each section has seven observation points, observed in the storage cavern by MDMI and TFL-ZLJ, which are the same points fisted in numerical simulation model.

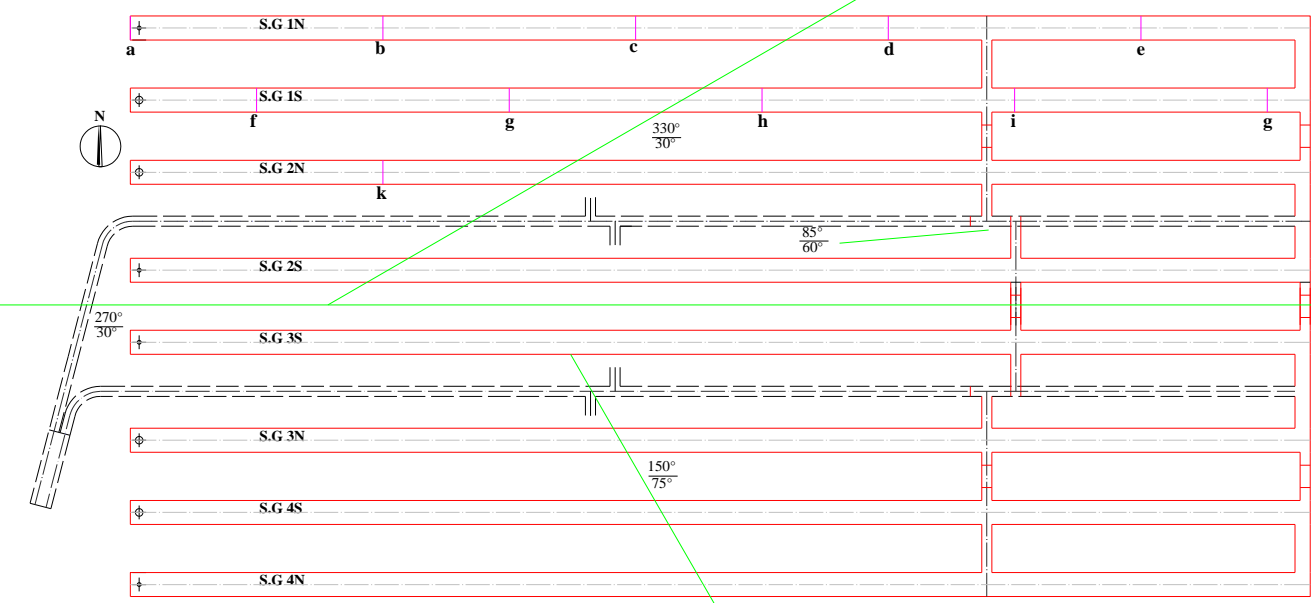



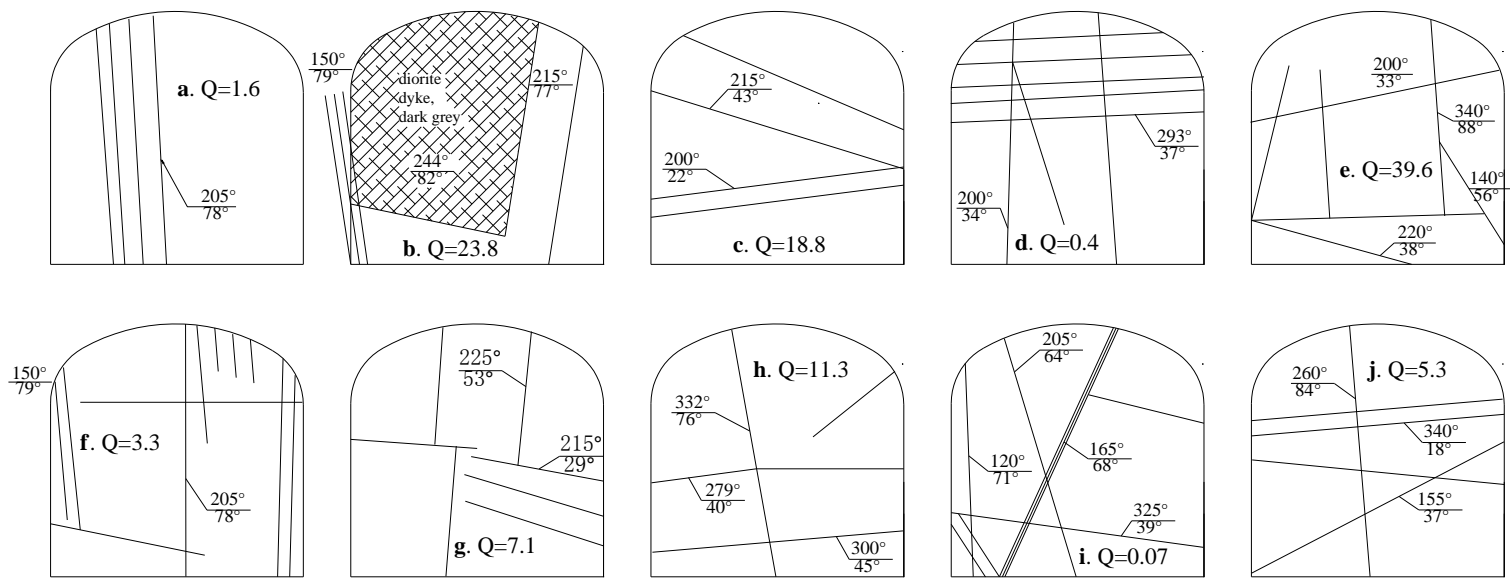

Figure 9. Typical sections of underground oil storage caverns for simulation and monitoring measurement

Figure 10. plots the comparison between numerical results and monitoring results of final displacements and stresses. Both displacements and stresses increase slowly with $\mathrm{Q}$ decreases at first when $\mathrm{Q} \geq 4$, then it grows sharply when $\mathrm{Q}<4$. Displacements in current oil storage caverns are millimeter-sized, and seven numerical curves and seven measured curves are almost the same shown in Fig. 9(a), except that point A provides the maximum of the displacements in some items. So we explored the correlation of Q values with measured displacements at observation point A. Hill1 model was adopted to describe the relationship between Q and DSPLA, with a perfect correlative coefficient as 0.99699. The correlation is as follows:

$$
D S P L_{A}=a_{0}-\alpha \frac{Q^{n}}{k^{n}+Q^{n}}
$$

Where $\mathrm{a}_{0}=13.87, \alpha=13.68, k=0.44, n=2.2386$,

Thereby predicting the displacement variation during tunneling excavation.

In the part of stress, monitoring data are a little larger than simulation data, especially in point $\mathrm{E}$ at the vault. But it is, generally, the trend is identical, numerical simulation results fit monitoring ones well.

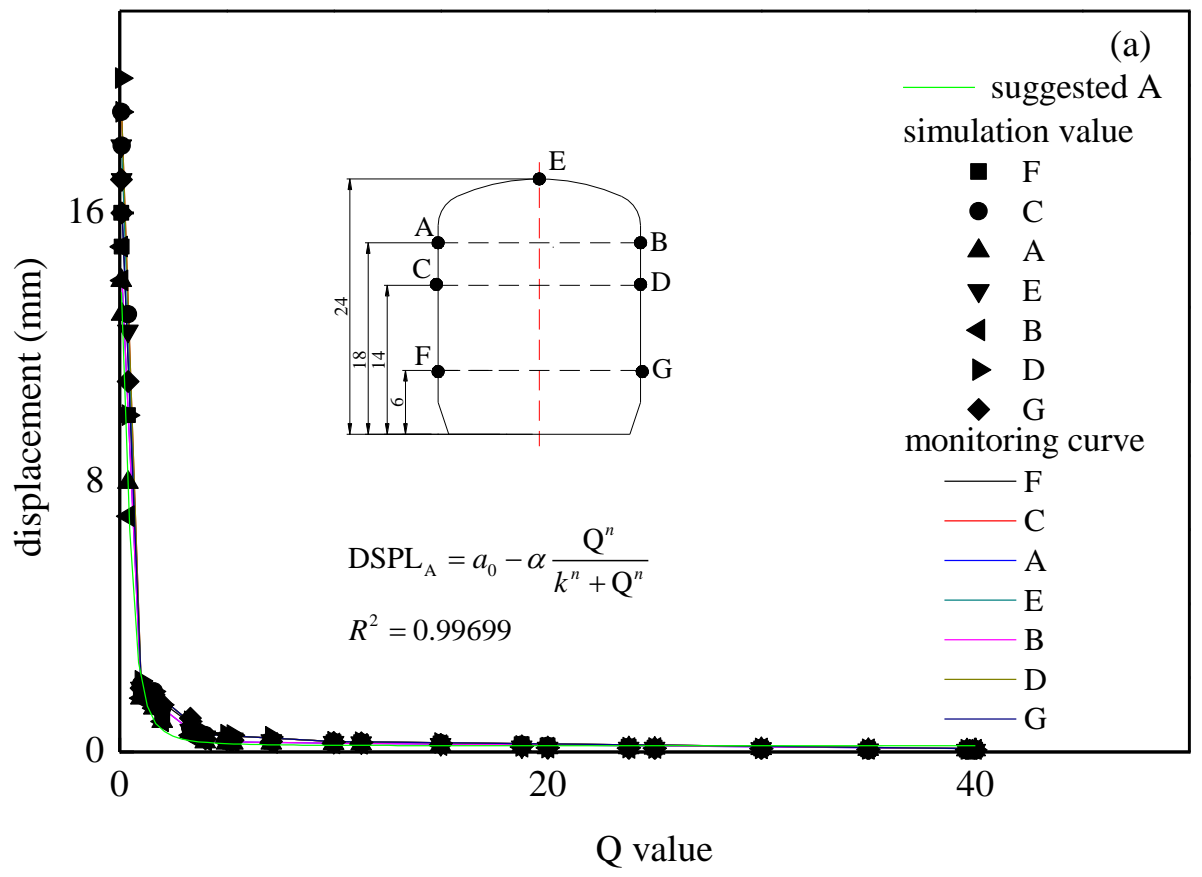




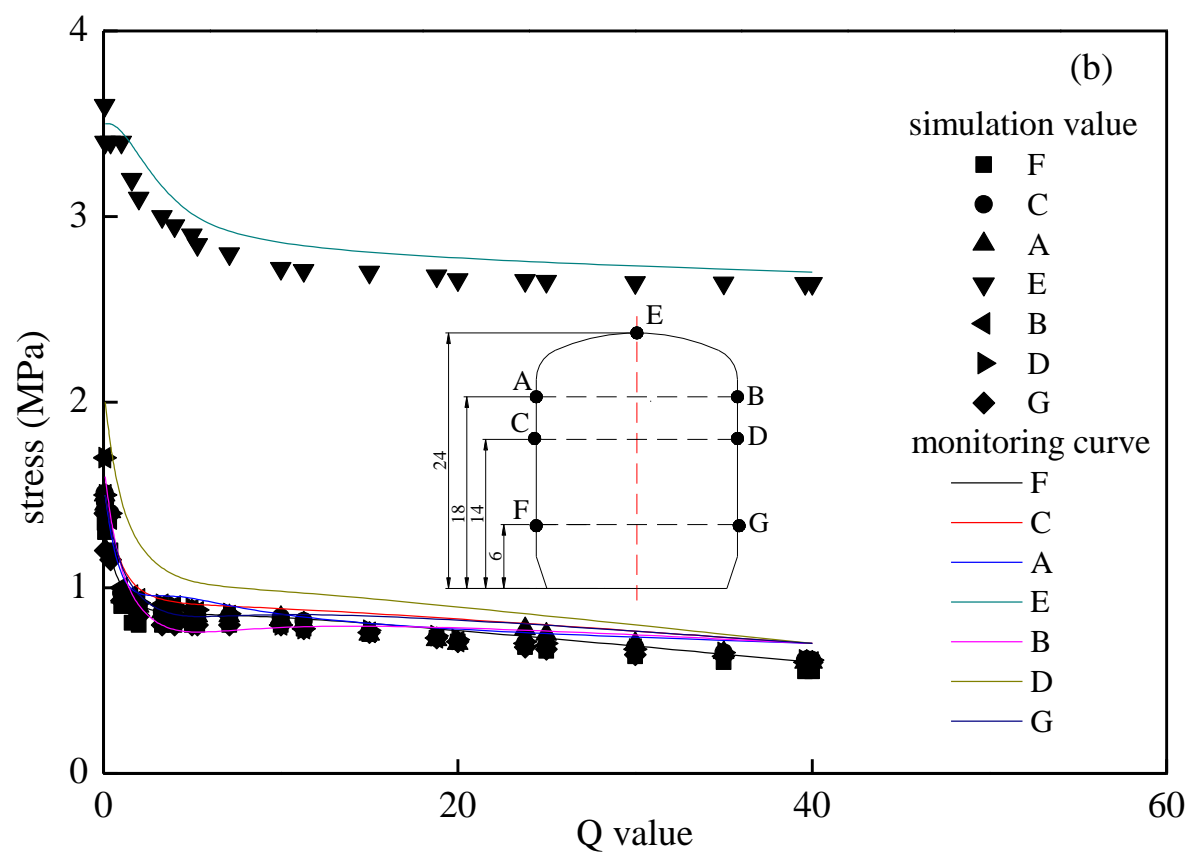

Figure 10. Comparison between numerical results and monitoring results

\section{Conclusion}

In this paper, correlations between friction angle, cohesion, tensile strength, deformation modulus, Poisson's ratio and $\mathrm{Q}$ were suggested by means of regression method with different mathematic models, thereby rapidly obtaining available parameters when it's hard to obtain the measured field data, which were recommended to use in underground storage projects basically with similar lithology. In addition, comparison of different criteria among Q-system and other codes for rock mass classification has been made to better understand the rock mass quality and applicability of Qsystem in underground oil storage project, which also helps to make a preliminary evaluation of rock mass quality in the practical engineering. Above proposed relationships were verified through numerical simulation and monitoring measurement and the calculated results of 3D tunnel excavation simulation are in good agreement with on-site test results. The above conclusions are specific to one underground oil storage caverns in China but could be relevant to other underground storage engineering under similar geological conditions.

\section{Acknowledgement}

We thank CREGC (20130503), Innovative Research Team in SWJTU (IRT0955), the Fundamental Research Funds for the Central Universities (SWJTU11ZT33), National Key S\&T Special Projects (2017YFB1201104) and China Scholarship Council (201407000040 \& 201306430001) for their sponsorships of this project, and we also thank the consultants and engineers contacted especially Jinzhou project department of China railway Erju Second engineering Co. Ltd during this study, for providing their data.

\section{References}

[1] Bai, Y., D. Q. Zhou, and P. Zhou. "Modelling and analysis of oil import tariff and stockpile policies for coping with supply disruptions." Applied energy 97 (2012): 84-90.

[2] Lin, Fang, et al. "TEM improves groundwater inflow estimates in undergound storage." Oil \& Gas Journal 113.11 (2015): $78-87$.

[3] Goel, Rajnish K., Bhawani Singh, and Jian Zhao. Underground infrastructures: planning, design, and construction. ButterworthHeinemann, 2012.

[4] Lin, Fang, et al. "Effectiveness analysis of water-sealing for underground LPG storage." Tunnelling and Underground Space Technology 51 (2016): 270-290.

[5] Terzaghi, Karl. "Rock defects and loads on tunnel supports." (1946).

[6] Deere, Don U. Technical description of rock cores for engineering purposes. University of Illinois, 1962.

[7] Bieniawski, Zdzisław Tadeusz. Engineering rock mass classifications: a complete manual for engineers and geologists in mining, civil, and petroleum engineering. John Wiley \& Sons, 1989.

[8] Bieniawski, Zdzislaw T. Rock mechanics design in mining and tunnelling. No. Monograph. 1984.

[9] Bieniawski, Z. T. "Engineering classification of jointed rock masses." Civil Engineer in South Africa 15.12 (1973). 
[10] Barton, N., Lien, R., \& Lunde, J. "Engineering classification of rock masses for the design of tunnel support. Rock Mechanics Felsmechanik M canique des Roches" (1974): 6, NO. 4, 189-236.

[11] Whickham, G. E., H. R. Tiedemann, and E. H. Skinner. "Support determination based on geological predictions." Proceeding of the North American Rapid Excavation and Tunnelling Conference. Vol. 1. 1972.

[12] Hoek, Evert, and Edwin T. Brown. "Practical estimates of rock mass strength." International Journal of Rock Mechanics and Mining Sciences 34.8 (1997): 1165-1186.

[13] Dhawan, A. K., and A. B. Joshi. "The Basic Approach to New Austrian Tunnelling Method." Symposium on Tunnelling, 52nd Board Session, CBIP. New Delhi. 1982.

[14] Grimstad, E. \& Barton, N. Updating of the Q-System for NMT. Proceedings of the International Symposium on Sprayed Concrete-Modern Use of Wet Mix Sprayed Concrete for Underground Support, Fagernes, 1993, (Eds Kompen, Opsahl and Berg. Norwegian Concrete Association, Oslo).

[15] Barton, N. "Some new Q-value correlations to assist in site characterisation and tunnel design". International Journal of Rock Mechanics and Mining Sciences (2002): 39, NO. 2, 185-216.

[16] Goel, R. K., J. L. Jethwa \& A. G. Paithankar. "Indian experiences with Q and RMR systems". Tunnelling and Underground Space Technology (1995): 10, 97-109.

[17] Choi, S. Y., \& Park, H. D. (2002). Comparison among different criteria of RMR and Q-system for rock mass classification for tunnelling in Korea. Tunnelling and Underground Space Technology, 17, NO. 4, 391-401.

[18] Palmström A. "Combining the RMR, Q, and RMi classification systems". Tunnelling and Underground Space Technology. (2009): 24(4): 491-492

[19] Tzamos S, Sofianos A I. "A correlation of four rock mass classification systems through their fabric indices". International Journal of Rock Mechanics and Mining Sciences (2007): 44(4): 477-495.

[20] Laderian, A. \& M. A. Abaspoor. "The correlation between RMR and Q systems in parts of Iran”. Tunnelling and Underground Space Technology (2011): 27, 149-158.

[21] Palmström, A., \& E. Broch. "Use and misuse of rock mass classification systems with particular reference to the Q-system", Tunneling and Underground Space Technology (2006): 21, NO. 6, 575-593.

[22] Anderson, T.L. Fracture Mechanics. CRC Press, second edition. Boca Raton, Florida. (1995).

[23] Read SAL, Richards LR, Perrin ND. "Applicability of the Hoek-Brown failure criterion to New Zealand greywacke rocks". In: Vouille G, Berest P, editors. Proceedings of the nineth international congress on rock mechanics, Paris, August, (1999): 2. 655-60.

[24] Mitri, H. S.; Edrissi, R. Henning, J. G. "Finite element modeling of cablebolted stopes in hard rock ground mines". SME Annual Meeting, (1994):14-17. New Mexico, Albuquerque.

[25] Hoek, E., \& Diederichs, M. S. "Empirical estimation of rock mass modulus". International Journal of Rock Mechanics and Mining Sciences (2006): 43, NO. 2, 203-215.

[26] Hoek, E., Brown, E.T. "Practical estimates of rock mass strength. International Journal of Rock Mechanics and Mining Science". (1997): 34, NO. 8, 1165-1186.

[27] Rutledge, J.C., Perston, R.L. "Experience with engineering classifications of rock”. In: Proc. Int. Tunnelling Sym., Tokyo, (1978): pp. A3.1-A3.7.

[28] Moreno Tallon, E. Application de Las Classificaciones Geomechnicas a Los Tuneles de Parjares, II Cursode Sostenimientos Activosen galeriasy Tunnels. Foundation Gomez-Parto, Madrid (Singh and Goel, 1999), 1980.

[29] Cameron-Clarke, I.S., Budavari, S. "Correlation of rock mass classification parameters obtained from bore core and insitu observations". Engineering Geology (1981): 17, 19-53.

[30] Abad, J., Caleda, B., Chacon, E., Gutierrez, V., Hidlgo, E. “Application of geotechnical classification to predict the convergence of coal mine galleries and to design their supports". In: 5th Int. Congress on Rock Mech., Melbourne, (E) (1984): pp. 15-19.

[31] Bieniawski, Z.T. Rock Mechanics Design in Mining and Tunnelling. A.A. Balkema, Rotterdam (1984).

[32] Gercek, H. "Poisson's ratio values for rocks". International Journal of Rock Mechanics and Mining Sciences (2007): 44, 1-13.

[33] Min, K.-B., Jing, L. "Stress Dependent Mechanical Properties and Bounds of Poisson's Ratio for Fractured Rock Masses Investigated by a Dfn-Dem Technique". International Journal of Rock Mechanics and Mining Sciences (2004): 41, NO. 3, CD-ROM. 